\title{
Non-invasive diagnosis and assessment of tricuspid regurgitation and stenosis using one and two dimensional echo-pulsed Doppler
}

\author{
COLETTE VEYRAT, D KALMANSON, M FARJON, J P MANIN, G ABITBOL \\ From Service de Cardiologie, Fondation A de Rothschild, Paris, France
}

SUMMARY Twenty normal subjects and 82 patients with valvular heart disease, whose lesions were ${ }^{\circ}$ independently assessed either by cardiac catheterisation and/or at operation, were studied using the 6 pulsed Doppler technique combined with either one or two dimensional echocardiography. Ofo these, 41 patients had tricuspid lesions, including 40 with regurgitation and nine with stenosis. The $\rightarrow$ tricuspid analogue flow velocity trace and the Doppler frequency spectrum (time interval histogram) $\subseteq$ were recorded. Characteristic differences were found between the records from subjects with and ${ }_{\Phi}$ without tricuspid lesions. In subjects with tricuspid regurgitation there was a systolic negative wave $\vec{\oplus}$ on the analogue velocity display and broadening of the time interval histogram. In subjects with tricuspid stenosis there was an abnormal pattern, and significantly increased duration of the diastolic 0 wave on the analogue velocity trace, again with broadening of the time interval histogram. Sensitiv- $\sum^{\circ}$ ity and specificity ranged between 85 and $95 \%$. The calculated ratio between the measured amp- $\frac{\partial}{\circ}$ litudes of the systolic and diastolic waves correlated well with independently performed grading of $\AA^{\circ}$ the regurgitation on a three point scale in $85 \%$ of cases. Grading of the severity of tricuspid stenosis $\stackrel{\odot}{\circ}$ on a three point scale based on studies of the diastolic Doppler velocity anomalies was the same in $\overrightarrow{\hat{O}}$ $85 \%$ of cases as the grading based on established invasive techniques. The addition of two dimen- $\exists$ sional echocardiography to the pulsed Doppler technique increased the sensitivity for mild lesions.

Invasive procedures do not solve all the diagnostic problems raised by tricuspid lesions, ${ }^{1-5}$ in spite of some helpful contributions from dye dilution, ${ }^{2}$ intracardiac phonocardiography, ${ }^{67}$ and angiography. ${ }^{8}$ Echocardiography, ${ }^{9-11}$ even when combined with contrast injections for the study of tricuspid regurgitation, ${ }^{1213}$ often lacks sensitivity and may give nonspecific diagnostic information, since it relies on peripheral or indirect data, such as motion of the interventricular septum. As early as 1970, continuous wave Doppler provided information on systemic venous return and led to a new diagnostic method for the evaluation of tricuspid disease. 14-16 The crucial advantage of pulsed Doppler, combined with either one dimensional ${ }^{17-24}$ or two dimensional ${ }^{25}$ echocardiography, is that it provides direct data from the site of the lesions. The present study was undertaken to evaluate the reliability of this new method when applied both to regurgitation and stenosis.

\section{Subjects and methods}

The study population included 20 normal subjects ( 12 women and eight men, mean age 28 years), and 820 patients ( 50 women and 32 men, mean age 38 years) in whom the presence of a tricuspid lesion was? confirmed or ruled out using classical invasive proce $-\rightarrow$ dures, that is right heart catheterisation (77 cases), with right ventricular angiography in 20 cases $N$ intracardiac phonocardiography in seven cases, dye dilution curves in nine cases, and assessment of the tricuspid valve at the time of surgery in 38 cases. $\omega$ Diagnoses included mitral lesions, pure (45) or com? bined with aortic valve (22) and/or tricuspid valve (21) disease, isolated aortic valve lesions (14), acute tricus ${ }_{\infty}$ pid endocarditis (four), chronic endomyocardia $\Gamma$ fibrosis (five), mitral and tricuspid prolapse (four) and congenital heart disease (10). Forty-seven patients were in sinus rhythm and 35 in atrial fibrilla $\frac{\rho}{8}$ tion. 


\section{DIAGNOSIS OF TRICUSPID LESIONS}

Tricuspid lesions were present in 41 patients consisting of $\mathbf{4 0}$ cases of regurgitation, eight of whom had associated stenosis, and one case of pure stenosis. With one exception the diagnosis was substantiated by at least two invasive procedures.

\section{CLASSIFICATION OF TRICUSPID LESIONS}

The severity of the tricuspid lesions was graded independently from the ultrasound findings on a three point scale, using the maximum information available in each case from cardiac catheterisation, pressure measurements, dye dilution, right ventricular angiography, and the surgical findings. This independent grading was grade 1 mild (19 lesions), grade 2 moderate (22 lesions), and grade 3 severe (eight lesions).

\section{APPARATUS}

We used an $\mathrm{ATL}^{\star} 3 \mathrm{MHz}$ pulsed Doppler velocimeter, combined either with a one dimensional echocardiograph (ATL $500 \mathrm{~A}$ ), or with a two dimensional $90^{\circ}$ wide angle mechanical sector scanner (ATL 851). Each device uses a single transducer for both techniques. The diameter of the transducer is $1.2 \mathrm{~cm}$ for the ATL $500 \mathrm{~A}$, and 2.5 for the ATL 851. According to the Doppler principle, the range gating system makes it possible to record the velocity of a small blood sample $(2 \times 4 \mathrm{~mm})$ at any given location along the ultrasonic beam from 3 to $17 \mathrm{~cm} .^{26}$ The output consists of three signals: (1) an audiosignal of the Doppler shift, (2) the time interval histogram, a form of spectral display of the Doppler signal, and (3) the analogue flow velocity trace. These two displays have been well described; ${ }^{26}$ in brief, the time interval histogram is produced by measuring the interval between two successive zero crossings of the Doppler audiosignal; the instantaneous Doppler shift is defined as the reciprocal of this interval; a dot is printed on the strip chart paper at a distance from the zero line which is directly proportional to the Doppler shift frequency. The analogue flow velocity trace corresponds to the mean value of the Doppler frequency shift and is obtained by frequency-to-voltage conversion of the audiosignal using zero crossing detection technique; its polarity may be reversed by a switch on the recorder.

We also used two video monitors, one for the real time scanning, and the other for the Doppler display. Recordings were made on a Sony video tape recorder. Hard copies of real time imaging were obtained on a 4633 Tektronix recorder. Doppler analogue flow velocity traces, TM echocardiographic tracings, Doppler spectral displays, as well as simultaneous electrocardiograms lead II, and frequency selecting phonocar-

* ATL, Bellevue, Washington, USA. diograms were recorded on an Irex I† fibreoptics recording system.

\section{RECORDING METHOD}

Tricuspid Doppler recordings were obtained by locating the transducer at the lower parasternal edge when using the one dimensional echo Doppler (37 cases). ${ }^{17}$ For two dimensional echo Doppler, we used the parasternal short axis (aortic valve and left ventricular level), apical four chambers, and subcostal views (45 cases), previously described for normal hearts. ${ }^{25}$

In brief, two dimensional echo Doppler recordings always required successively: (1) dynamic scanner visualisation of the tricuspid valve, (2) location of the Doppler beam at the desired angle to the tricuspid valve, (3) adjustment of the Doppler gate to control the depth of the sample volume along that beam. This was achieved by obtaining a good two dimensional scan of the right heart cavities and of the tricuspid valve, and then the axis of the Doppler beam seen as a continous white line was swept across the scan plane by moving a lever on the probe until it crossed the tricuspid valve at the desired angle. The Doppler gate, seen as a bright spot, was adjusted using a control on the probe. The image was then frozen while the apparatus was automatically switched to the Doppler system. When the characteristic Doppler sound was heard, the recording was made. We recorded several samples at the annulus: at least one at the centre of the annulus and one at the commissures.

\section{VARIABLES STUDIED}

The study involved the analysis of both the analogue and the spectral displays.

\section{(1) Analogue flow velocity traces}

These were examined for the presence or the absence of a systolic negative wave, its amplitude, duration, and spatial annular extension, and also for the diastolic pattern.

(a) When a negative wave was present, an index of its magnitude was calculated: the negative/positive $(\mathrm{N} / \mathrm{P})$ ratio. This was obtained for each recording in the following manner (Fig. 1): the amplitude of the negative wave was measured at two points in systole, the first (N1) $70 \mathrm{~ms}$ after the first heart sound, and the other (N2) 70 ms before the second heart sound as shown on the phonocardiogram. The maximum diastolic positive deflection $(P)$ from the trace was measured and the mean of the ratios $\mathrm{N} 1 / \mathrm{P}$ and $\mathrm{N} 2 / \mathrm{P}$ was

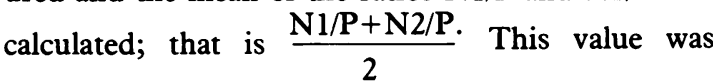
obtained for each recording. Where there were only two recordings, the mean of the two $N / P$ values was

† Irex, Mahwah, NJ, USA. 


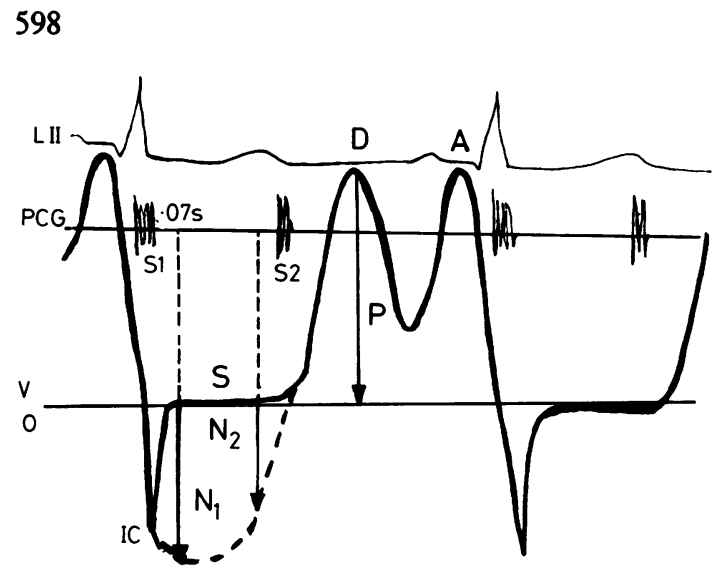

Determination of the N/P ratio

Fig. 1 Schematic representation of the tricuspid flow velocity trace, with determination of the N/P ratio (systolic segment: full line, normal; thick dashed line, abnormal negative wave seen in patients with tricuspid regurgitation; $V$, analogue flow velocity trace; 0 , zero line; LII, lead II of the electrocardiogram; PCG, phonocardiogram; $S 1$ and S2, first and second heart sounds; IC, brief negative deflection caused by the isometric contraction; $S$, systolic segment; " $D$ " and " $A$ ", early- and end-diastolic positive filling waves; N1 and N2, amplitude of the negative wave calculated in centimetres from the zero line; $P$, maximal amplitude of the positive diastolic wave calculated in centimetres from the zero line). The systolic negative depth is measured in two points of systole: $-0.07 \mathrm{~s}$ after the end of the first heart sound (N1), and -0.07 s before the second sound (N2); it is then related to the amplitude of the " $D$ " wave $(P)$; the same manoeuvre is repeated on another blood velocity sample examined at the annulus, and the overall mean is calculated.

calculated. Where more than two recordings were available, the most disparate values of $\mathrm{N} / \mathrm{P}$ were used to obtain the mean. Where one of these was zero, the other value was divided by two.

(b) The duration of the early diastolic filling wave (D) was measured for patients with atrial fibrillation. The time interval was corrected for heart rate by the Bazett ${ }^{27}$ formula. The mean of values from five cardiac cycles was obtained for each recording.

\section{(2) Frequency spectrum}

This was examined for the presence or absence of a spectral broadening when the Doppler sample volume was at any point of the annulus or in the right atrium. Spectral broadening was considered abnormal when the dispersion of the dots was present on the time interval histogram according to the following criteria: (1) use of the minimal Doppler gain compatible with the recommended signal to noise ratio judged from the bottom trace on the monitor called "signal amplitude" (Fig. 2), (2) amplitude of the dispersion at least twice as wide as that seen on the spectrum for laminar flow in segments of the same cardiac cycle,
Veyrat, Kalmanson, Farjon, Manin, Abitbol $\stackrel{\frac{0}{\top}}{\stackrel{\Phi}{\Phi}}$

(3) duration of the disturbance equal to or greater than $0 \cdot 10 \mathrm{~s}$, and (4) absence or interference from any cardiac structure motion.

Analysis of the Doppler data was made withouto knowledge of the results of the invasive procedures. $A$ 듬 statistical analysis of the results was performed using a Hewlett Packard 4815 with determination of: (1) the mean value and standard deviation for the duration of the diastolic filling (D) wave in cases of atrial fibrilla- ${ }^{-}$ tion and for the N/P radio in cases of regurgitation; $\vec{\circ}$ (2) the significance of the differences found between different grades of severity for the latter, assessed $\omega_{\sigma}$ using the Student test ( $t$ and $P$ ); (3) the linear regression equations between the calculated Doppler data and the haemodynamic variables.

\section{Results}

NORMAL SUBJECTS

Fig. 2 shows the normal pattern of the tricuspid flowe velocity trace both for analogue and spectral display, using the two dimensional echo Doppler. Neither an abnormal spectral broadening nor a systolic negativity was noted during the cardiac cycle.

\section{PATIENTS WITH TRICUSPID LESIONS Diagnosis}

(1) Tricuspid regurgitation (Figs. 3 and 4). The presence of an abnormal systolic negative wave and/or of $\frac{1}{2}$ spectral broadening was noted in 41 patients. In 35 of these patients, tricuspid regurgitation was proveng (sensitivity: $87 \%$, and specificity: $85 \%$ ). Five falsenegative diagnoses were found in patients with mild regurgitation, four of whom were studied with one dimensional echo Doppler only. False positive diag $\mathbb{\mathbb { N }}$ noses were equally common using the two echo pro? cedures.

(2) Tricuspid stenosis (Fig. 5). In 10 cases, dias

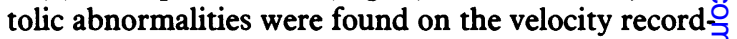
ings where the corresponding Doppler sound was higher pitched; with the Doppler sample at one or? several points of the annulus, the " $D$ " summit of the analogue trace was cut off and replaced by an inden ted horizontal plateau or gently ascending slope withs broadening of the corresponding part of the $\operatorname{spec}_{\pi}$ trum. In six patients with atrial fibrillation, 2 significant increase in duration of the " $D$ " wave was" noted (Table 1 and Fig. 6). Of these 10 cases, tricus? pid stenosis was confirmed in eight cases by the inva을

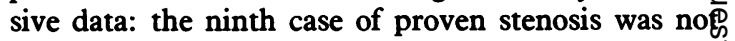
found by Doppler (sensitivity: $88 \%$, specificity: $97 \%)+$ In one false positive case, external compression of the tricuspid annulus caused by a huge left atrium wa® found during operation. Fig. 7 illustrates the overalf results (sensitivity, specificity, predictive value, an accuracy of the method). 

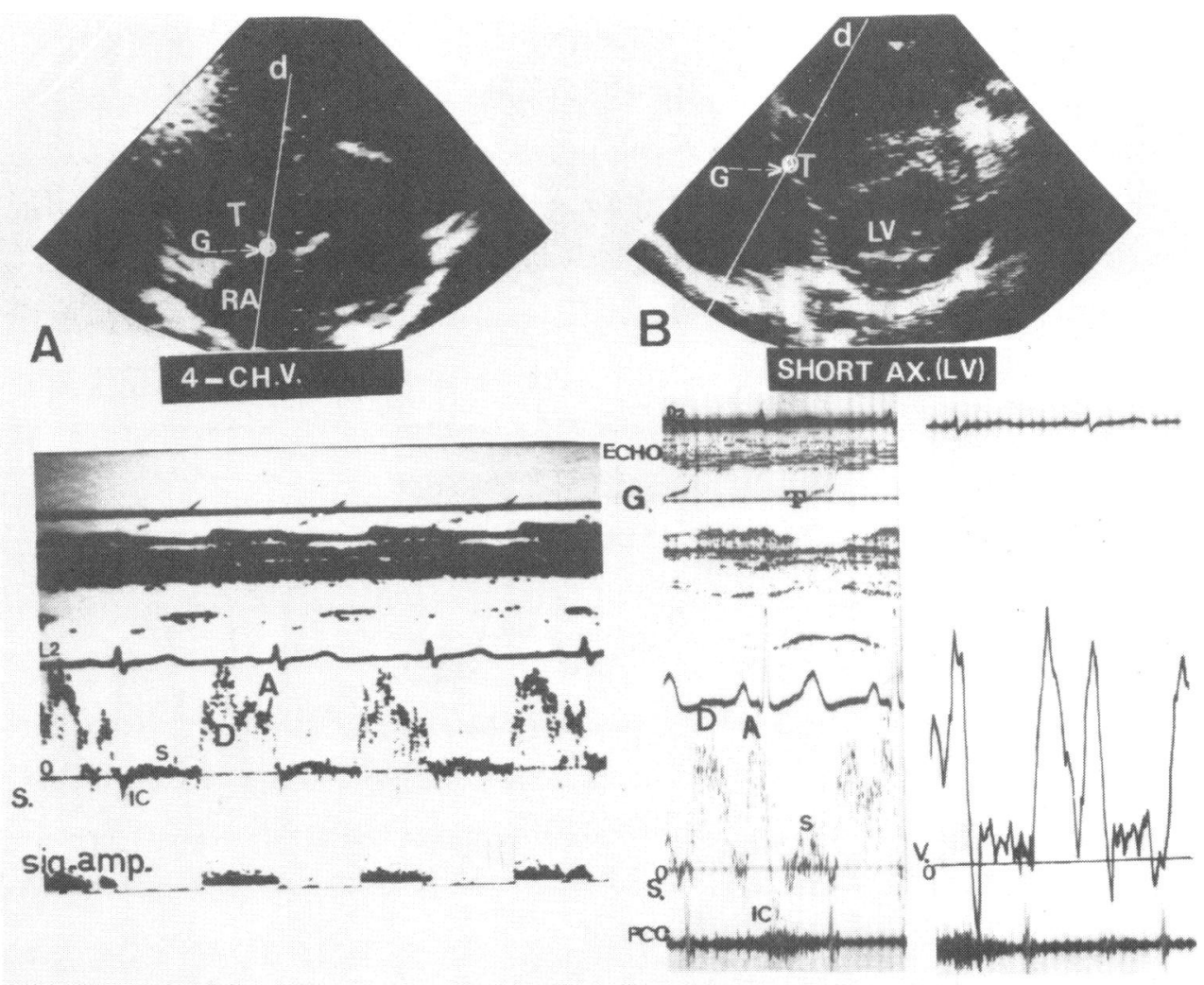

Fig. 2 Normal subject: tricuspid flow velocity trace obtained using two dimensional echo Doppler (d, Doppler beam; $T$, tricuspid valve; $G$, Doppler gate; $R A$, right atrium; $L V$, left ventricle; $E C H O, T M$ echocardiographic visualisation; $S$, frequency spectrum (time interval histogram); sig. amp., signal amplitude; other abbreviations as in Fig. 1). Here, two different approaches are used to visualise the tricuspid valve: $(A)$ on the left, using the apical four chamber view, $(B)$ on the right, using the left ventricular short axis view; the Doppler gate (seen as a white point) has been moved along the Doppler beam (seen as a white line) to the level of the tricuspid valve: the characteristic normal tricuspid flow velocity pattern is displayed, both on the spectrum (bottom left and middle) and on the analogue (bottom right). Four segments are shown: the " $i c$ " deflection lined up with the first sound; the " $S$ " segment near to the zero line because of the absence of forward flow in systole and the two positive waves of forward flow, the early diastolic " $D$ ", and the end-diastolic " $A$ " related to atrial contribution to the ventricular filling. Note the smooth pattern of the diastolic summits, and the absence of any noticeable spectral broadening. In $A$, the gate was intentionally located a little higher than the annulus to show the effects of the valvular motion on the spectrum: brief transient dispersion of the dots is elicited, without pathological significance.

Assessment of severity of lesions

(1) Tricuspid regurgitation (Fig. 8 and Table 2). A significant increase in the $N / P$ ratio between each grade of severity was found. Satisfactory grading of severity was obtained from Doppler data in $85 \%$ of cases, with two underestimations and one overestimation.

(2) Tricuspid stenosis. The assessment of the severity was satisfactorily obtained in $87 \%$ of cases, with one overestimation. The indented pattern was found at the commissures in two mild lesions o: 4 l of three, and spread nearer to the centre in the five cases of moderate stenoses. No satisfactory recording could be obtained in diastole in one case of severe stenosis.

Correlations between N/P ratio, diastolic filling wave duration, and haemodynamic variables (Tables 1 and 2) No significant difference between the three grades of severity was found for the mean value of the " $v$ " wave, the mean right atrial pressure, or the systolic right ventricular pressure. No satisfactory linear correlation was found between those variables and the measurements performed on Doppler data. 

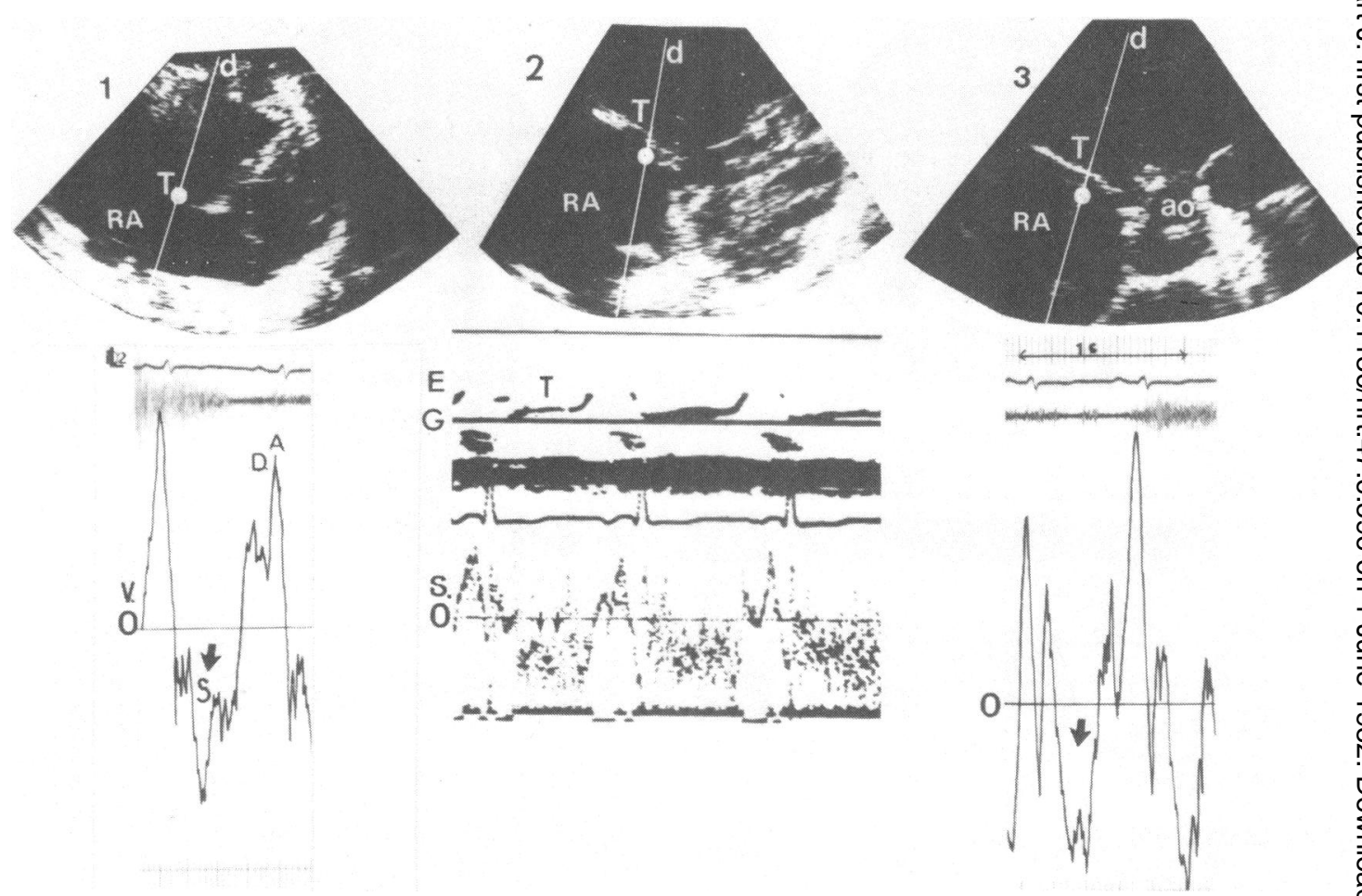

Fig. 3 Chronic endomyocardial fibrosis with severe tricuspid regurgitation (same abbreviations as in Fig. 2, ao, aortic valvular area). (1) Four chamber view: the gate is located at the level of the tricuspid valve and the bottom panel shows a conspicuous negative $S$ wave (thick arrow). (2) Left ventricular short axis view: the spectral curve at the bottom is abnormal in systole, showing pronounced and prolonged broadening with presence of backward flow (small arrows). (3) Aortic valvular area short axis view: the abnormal systolic negative wave is also displayed using this approach. No normal systolic pattern could be recorded in this case of severe regurgitation resulting from annular dilatation.

\section{PATIENTS WITHOUT TRICUSPID LESIONS}

With the exception of the false Doppler diagnoses already mentioned the recordings were similar to those of normals. Disappearance of the " $A$ " wave was observed in cases of atrial fibrillation; the " $D$ " wave was normal in these patients (Fig. 9).

\section{Discussion}

The comments will be focused on (1) the technical limitations of the pulsed Doppler technique, (2) the recall of the respective advantages of one and two dimensional echo Doppler, (3) the results for regurgitation, and (4) stenosis.

\section{(1) TECHNICAL LIMITATIONS}

Though the empirical relations between the velocity traces obtained and the flow disturbances of tricuspid valve disease cannot be disputed, and the shapes of the velocity traces both in normal subjects and in those with tricuspid valve disease are similar to those recorded using continuous wave Doppler catheters $\frac{1}{\frac{9}{5}}$ and electromagnetic flowmeters, ${ }^{28}$ there are technica $\mathrm{D}$. limitations of the technique which put some con: straints on the interpretation of these velocity traces (1) Absolute velocities cannot be calculated since the angle $\theta$ between the ultrasound beam and blood flow direction is unknown, and neither the time intervas histogram nor the analogue velocity display are cali brated. (2) Pulsed Doppler imposes a conflict beo tween the use of high pulse repetition frequency for the measurement of high velocities and the loweft pulse repetition frequency required for recordings any depth, the so-called "Nyquist limit". (3) Spectrô broadening on the time interval histogram, commonlo accepted as an indication of turbulence in the sample volume, may also arise if the Nyquist limit is exceeded and is very susceptible to observer control.

Some of these limitations are less serious for tricus pid valve disease than for mitral valve disease, sinat the tricuspid valve is closer to the chest wall and the blood velocities tend to be lower. 


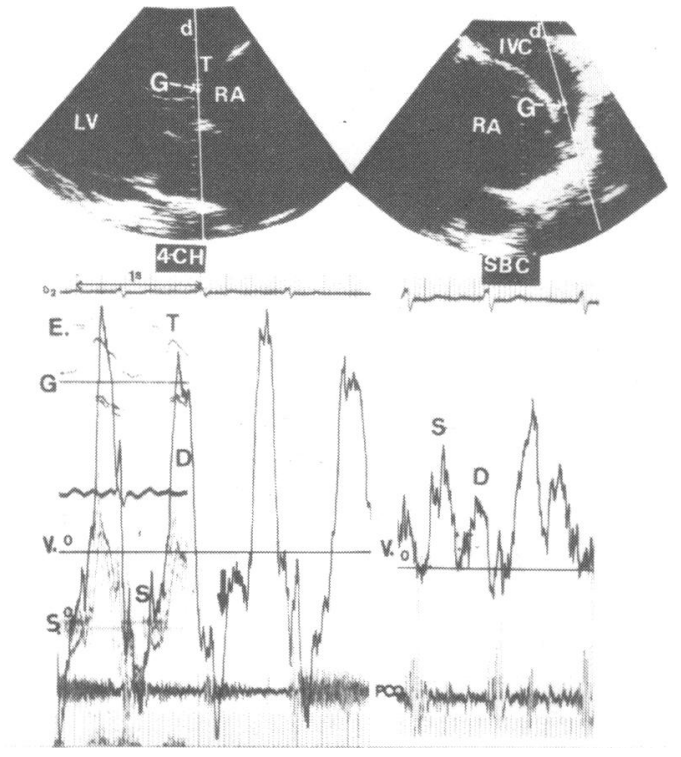

Fig. 4

Fig. 4 Moderate tricuspid regurgitation: tricuspid versus caval detection for the diagnosis of the regurgitation (same abbreviations as in previous figures, SBC, subcostal approach; IVC, inferior vena cava). On the left, four chamber view, the gate is located at the tricuspid valve: signs of tricuspid regurgitation are elicited on the Doppler displays at the bottom (thick arrow lining with the systolic negative wave). On the right, the gate is moved towards the vena cava, using the subcostal approach: the regurgitation is missed since there is a normal pattern of the systolic part of the caval flow velocity.

Fig. 5 Pulsed Doppler recordings in tricuspid stenosis (same abbreviations as before, $M$, mitral valve; TIH, time interval histogram). This figure shows two recordings at the tricuspid valve: in 1 (top left panel), the gate has been located at the centre of the tricuspid orifice (indicated by 1 on the scanner view in the middle panel): though some indentations may be seen on the analogue trace, the general normal diastolic pattern is recognisable with the separate " $D$ " and " $A$ " waves. In 2 (top right panel) the gate has been located next to the commissural area (indicated by 2 on the scanner view): a typical stenosed indented pattern is recorded with progressive ascent toward the end of the diastole (oblique arrows). This patient had a mild pure stenosis with a pressure gradient of $3 \mathrm{mmHg}$. This figure shows the need for several Doppler recordings at a given orifice, in order not to miss a mild lesion.

1
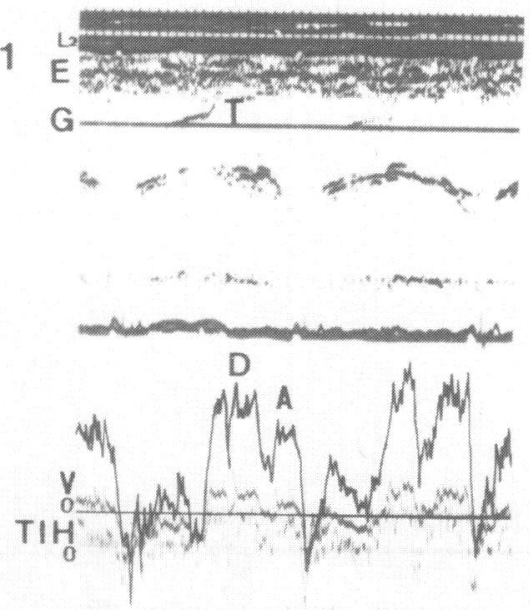

\section{2}
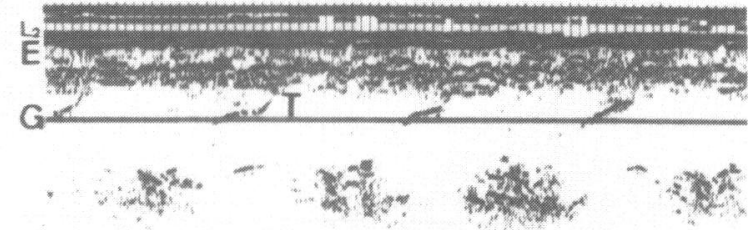

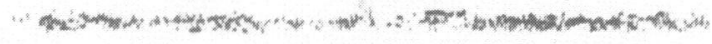

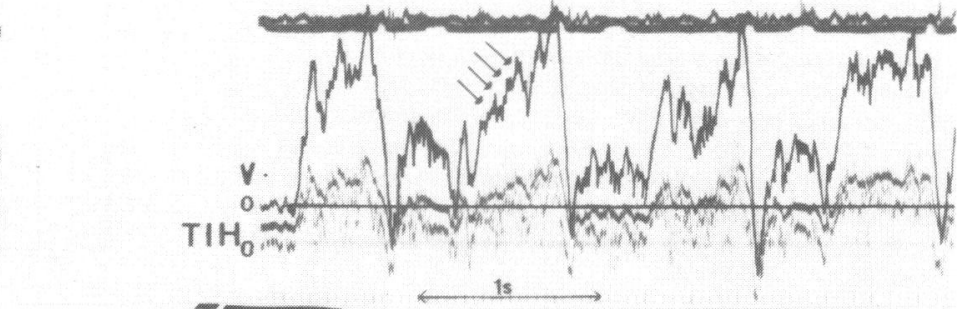

Fig. 5 
Table 1 Duration of filling " $D$ " wave in patients with atrial fibrillation with and without tricuspid disease

\begin{tabular}{|c|c|c|c|}
\hline & Patients without tricuspid disease & Patients with tricuspid regurgitation & Patients with tricuspid stenosis \\
\hline \multirow{2}{*}{ 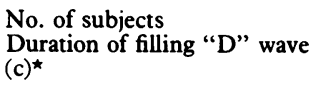 } & 12 & 12 & 6 \\
\hline & $0.29 \pm 0.04$ & $0.33 \pm 0.06^{\star \star}$ & $0.51 \pm 0.06^{\star \star \star}$ \\
\hline
\end{tabular}

Correlation between mean right atrial pressure/DFW: $y=17.92 . x+1.46 \quad r=0.41$.

*Duration of filling " $D$ " wave (c), with correction for heart rate, expressed in seconds.

$\star \star \star \mathrm{p}<0.001 ; \quad \star \star \star \mathrm{p}<0.05$

Note: Significant increase in duration of forward flow in cases of organic stenosis obvious in spite of the limited number of stenotic cases and of the discrete character of the stenosis in a third of the cases. No satisfactory linear correlation appears between this duration and the value of the mean of the right atrial pressure.

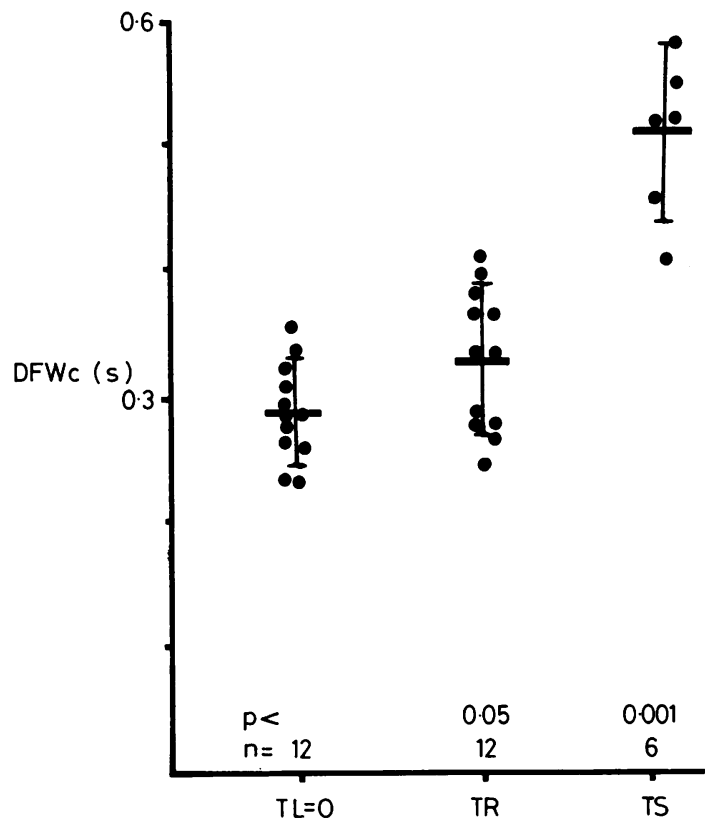

Fig. 6 Duration of the filling wave in patients with and without tricuspid lesion and with atrial fibrillation $(T L=0$, patients without tricuspid lesions; $T R$, tricuspid regurgitation; $T S$, tricuspid stenosis; $D F W c$, duration of the diastolic filling wave " $D$ ", with correction for heart rate). The mean values (horizontal bars) and the standard deviations (vertical bars) are indicated, and also the individual values. A significant increase of the duration of the " $D$ " wave was observed in patients with stenoses.

One of our criteria for the assessment of a disturbed spectrum needs some comment: the reference to a normal segment in the cardiac cycle could be inadequate when combined lesions are present, but, in our experience, it was always possible to find a normal segment for comparison in such cases.

(2) TWO DIMENSIONAL ECHO DOPPLER VERSUS

ONE DIMENSIONAL ECHO DOPPLER

The placement of the sample volume was much easier with the two dimensional echo which enabled a more accurate investigation of the annulus and of the com missures. This fact probably explains the lower rate of false negative results for the diagnosis of mild regurgi- $\dot{\omega}$ tation when using this apparatus. On the other hand, $\mathscr{\circ}$ the signal to noise ratio was less good for the Doppler,윽 and the probe less handy in this equipment than in the one dimensional device.

\section{(3) RESULTS FOR TRICUSPID REGURGITATION}

Fig. 4 illustrates the need for recording direct data ono tricuspid flow disturbances for a reliable assessment of lesions. This requirement is fulfilled by the use of the pulsed Doppler technique. We have already men tioned the advantages of the use of the two dimeno sional equipment for avoiding false negative results

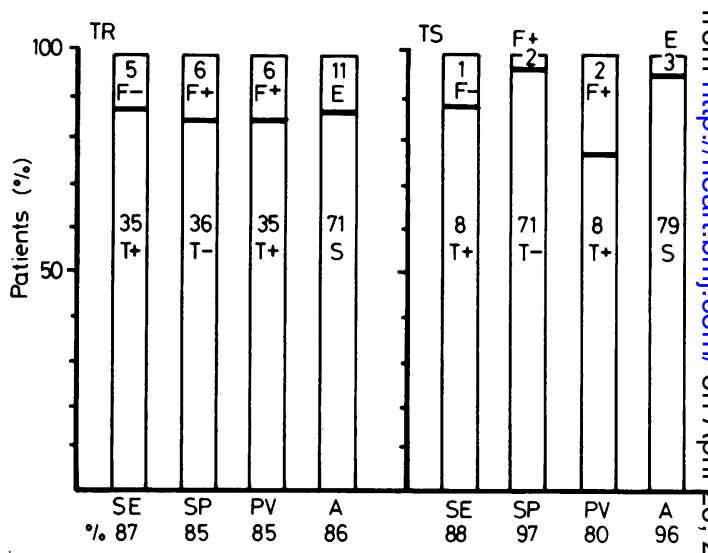

Fig. 7 Correlative data between pulsed Doppler echocardiography and invasive procedures for diagnosis of tricuspid lesions (TR, tricuspid regurgitations; $T S$, tricuspid stenosis; SE, sensitivity; SP, specificity; $P V$, predictive value; $\mathbb{\Phi}$ $A$, accuracy of the method; $F+$, false positive diagnoses using $?$ pulsed Doppler; $F$-, false negative diagnoses using pulsed Doppler; $T+$, true positive diagnoses using pulsed Doppler confirmed by invasive procedures; $T$-, true negative diagnoses $\mathbb{D}$ using pulsed Doppler confirmed by invasive procedures; $S$, total $\underset{\mathbb{Q}}{ }$ successful diagnoses using pulsed Doppler; $E$, total wrong diagnoses using pulsed Doppler). 
Table 2 Value of N/P ratio and of haemodynamic variables involved in correlative study for patients with tricuspid regurgitation

\begin{tabular}{|c|c|c|c|c|c|}
\hline $\begin{array}{l}\text { No. of patients } \\
(34) \\
N / P\end{array}$ & $\begin{array}{l}\text { Tricuspid re } \\
\text { Grade } 1 \\
(9) \\
0.21 \pm 0.11\end{array}$ & $\begin{array}{l}\text { Gration } \\
\text { Grade } 2 \\
(19) \\
0.44 \pm 0 \cdot 15 \\
\star\end{array}$ & $\begin{array}{l}\text { Grade } 3 \\
(6) \\
0 \cdot 75 \pm 0 \cdot 11 \\
\star \star\end{array}$ & $\begin{array}{l}\text { Correlation between N/P ratio and haemodynamic } \\
\text { variables }(n=28)\end{array}$ & \\
\hline \multirow{3}{*}{$\begin{array}{l}\text { "v" wave } \\
\text { Mean right atrial pressure } \\
\text { (mmHg) } \\
\text { Right ventricular systolic } \\
\text { pressure (mmHg) }\end{array}$} & $6 \pm 3$ & $11 \pm 4$ & $14 \pm 8$ & \multirow{3}{*}{$\begin{array}{c}\text { v wave }=6.49 \mathrm{~N} / \mathrm{P}+7.34 \\
\text { Mean right atrial pressure } \\
(\mathrm{mmHg})=2.79 \mathrm{~N} / \mathrm{P}+7.54 \\
\text { Right ventricular systolic } \\
\text { pressure }=-4.49 \mathrm{~N} / \mathrm{P}+43.82\end{array}$} & $r=0.26$ \\
\hline & $7 \pm 3$ & $9 \pm 3$ & $10 \pm 4$ & & 0.14 \\
\hline & $39 \pm 13$ & $45 \pm 16$ & $45 \pm 31$ & & 0.02 \\
\hline
\end{tabular}

$\mathrm{N} / \mathrm{P}$, ratio of amplitude of negative systolic wave, related to that of the diastolic positive wave.

${ }^{\star} p<0.01$.

$\star \star \mathrm{p}<0.001$.

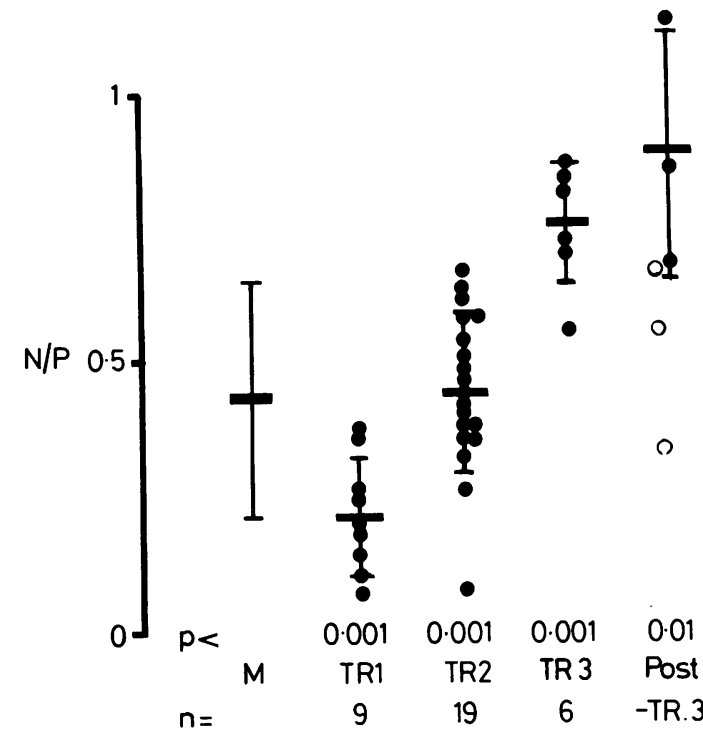

Fig. 8 Semiquantitative assessment of severity of regurgitation using N/P ratio. Left column, overall mean $(M)$ (horizontal bar) with the standard deviation (vertical bar) for the patients with tricuspid regurgitation (TR); second to fourth columns: mean values of the N/P ratio according to the grading of increasing severity ( 1 mild, 2 moderate, 3 severe); $p, p$ values for each grade of severity; last column on the right: three patients were examined before $(0)$ and after $(\bullet)$ removal of the tricuspid valve

(Post-TR); the tricuspid removal was followed by a significant increase in the N/P ratio.

In spite of these advantages and resultant more accurate checking of the sample, the false positive percentage was equal for both types of equipment. Since there is no gold standard for evaluation of tricuspid regurgitation, one logical explanation for our findings of negative systolic velocity at the tricuspid annulus in some patients not diagnosed as having tricuspid regurgitation was that the Doppler technique is more sensitive and, therefore, superior to other techniques of tricuspid valve assessment. Among these, angiography appeared the most reliable, as we found only one false positive Doppler diagnosis when this procedure was used for the correlative study.

The correlation of both displays (analogue and spectral) increased the diagnostic sensitivity; the reason was that some cases of mild regurgitation could only be shown on the spectrum and not on the analogue display, and, conversely, some cases of free regurgitation, described as "silent" during intracardiac phonocardiographic procedures, ${ }^{6}$ coexisted with apparently laminar flow. Two different procedures have been described to assess the severity of the tricuspid regurgitation: an index of systolic turbulence $^{23}$ and the calculation of the N/P ratio ${ }^{22}$; in our experience, the characteristics in amplitude and duration of the spectral broadening appeared less reliable than the calculation of the N/P ratio, and were not taken into account for grading the severity. The evaluation of the severity therefore only relied, in the present study, on the measurement of the N/P ratio; we are aware that at least three factors prevent an accurate quantification of tricuspid regurgitation: (1) the somehow arbitrary selection of the two samples at the annulus, (2) the unknown angle $\theta$ which, moreover, could vary if the heart moves and if forward and reverse flow are not at $180^{\circ}$ to each other, and (3) the variations in size of the tricuspid annulus during the cardiac cycle. ${ }^{29}$ In spite of these limitations, our index proved to be clinically very useful for a semiquantitative evaluation of tricuspid regurgitation. Discrepancies in Doppler grading were generally related to unrepresentative samplings in the presence of low cardiac output leading to underestimation, or of exceptionally poor echo visualisation. The lack of satisfactory correlation between the $\mathrm{N} / \mathrm{P}$ ratio and the haemodynamic variables may be explained by the presence of nearly normal pressures in several patients with significant lesions.

\section{(4) RESULTS FOR TRICUSPID STENOSIS}

These preliminary results suggest high diagnostic reliability of the pulsed Doppler technique. In two cases, the Doppler technique appeared even more 
Fig. 9 Tricuspidflow velocity recording in patient with atrial fibrillation but without tricuspid lesion (same abbreviations as in previous figures, $M V$, mitral valve; $L A$, left atrium; $R V$, right ventricle; $T V$, tricuspid valve). There is a disappearance of the " $A$ " wave with an early diastolic " $D$ " wave of normal duration. The systolic wave is normal. (Each vertical bar interval $=0.04 \mathrm{~s}$.)

reliable than cardiac catheterisation since Doppler studies showed anomalies, diagnostic of tricuspid stenosis, where cardiac catheterisation disclosed no significant tricuspid pressure gradient; at operation, the valve was found to show commissural fusion and appeared typically stenosed. Severe tachyarrhythmia was the reason for a false negative result in one case where no adequate diastolic flow recording could be obtained. External compression of the orifice was found to have the same consequences upon flow as valvular stenosis and may, therefore, occasionally cause confusion.

The significantly increased duration of the early diastolic filling wave was a reliable and sensitive sign of stenosis in patients with atrial fibrillation, where the lack of " $A$ " wave could make the pattern anomalies less obvious. This timing anomaly helped to avoid confusion with the increased diastolic flow component seen in patients with severe regurgitation, since there is no appreciable overlap between the respective values in both groups (Fig. 6). The evaluation of the severity was not based on the time interval histogram because of its limitations; a more quantitative approach may be expected from the use of Doppler real time spectral frequency analysers recently available. For instance, the analysers may perform the transform by numerous multiplications and additions of discrete Doppler time samples with frequency sweeps called "chirps" ( $\mathrm{Z}$ chirp transform), ${ }^{30}$ or may use a digital fast Fourier transform. ${ }^{31}$ In our study, $\frac{\circ}{\otimes}$ the assessment relied on a pattern recognition method $\stackrel{2}{\rightarrow}$ taking into account the central and commissural velocity patterns which appeared clinically reliable. No relation between the duration of the filling wave and the severity of the stenosis could be established in our limited number of cases, and this needs further investigation.

\section{Conclusion}

Provided that some methodological rules are observed, the pulsed Doppler technique seems the $\frac{}{5}$ most reliable non-invasive method so far developed $\rightarrow$ for assessment of tricuspid lesions; its reliability was maintained even in patients with atrial fibrillation and $\tilde{N}$ heart failure, and was independent of the level of right ${ }^{\circ}$ ventricular pressure.

\section{References}

1 Cairns KE, Kloster FE, Bristow JD, Lees MH, Griswold HE. Problems in the hemodynamic diagnosis of tricuspid? insufficiency. Am Heart $\mathcal{f}$ 1968; 75: 173-9.

2 Hansing CE, Rowe CG. Tricuspid insufficiency: a study $\bar{P}^{\circ}$ of hemodynamics and pathogenesis. Circulation 1972; 45: ()

3 Kawashima Y, Nakano S, Manabe H. Tricuspid insuffi- $\frac{\overparen{D}}{\square}$ ciency: a study of hemodynamics. Fpn Circ $\mathcal{F} 1974 ; 38$. 853-9. 
4 Rubeiz GA, Nassar ME, Dagher IK. Study of the right atrial pressure pulse in functional tricuspid regurgitation and normal sinus rhythm. Circulation 1964; 30: 190-3.

5 Savier CH, Kin G, Facquet J. Sur une nouvelle méthode d'évaluation des insuffisances valvulaires à partir des courbes de dilution. Arch Mal Coeur 1963; 56: 993-1003.

6 Delzant JF, Forman J, Machado C, Calisti G. Insuffisance tricuspidienne fonctionnelle et organique (à propos de 60 cas étudiés par cathétérisme et phonocardiographie intracavitaire). Arch Mal Coeur 1968; 61: 305-32.

7 Forman J, Varin G, Fouchard J. Le rétrécissement tricuspidien. In Soulie $\mathrm{P}$, ed. Le cathétérisme des cavités droites et gauches du coeur au micromanomètre. Paris: Baillière, 1971: 291-305.

8 Geshwind H, Tenaillon A, Samii K, Nitenberg G, Farah E. Evaluation des lésions tricuspidiennes par la cinéangiographie. Coeur 1975; 6: 687-703.

9 Feigenbaum H. Echocardiography. 2nd ed. Philadelphia: Lea \& Febiger, 1976.

10 Escojido H, Salomon H, Bousquet JP, et al. Apport de l'échocardiographie au diagnostic des valvulopathies tricuspidiennes rhumatismales. A propos de 103 cas. Arch Mal Coeur 1978; 71: 1083-9.

11 Grimberg D, Kechrid R, Halphen C, Acar J. Approche échocardiographique des valvulopathies tricuspidiennes. Rev Lat Cardiol 1980; 1: 115-21.

12 Kisslo JA. Usefulness of $\mathrm{M}$-Mode and cross-sectional echo-cardiography for analysis of right-sided heart diseases. In Lancee CT, ed. Echocardiology. The Hague; Martinus Nijhoff, 1979: 37-47.

13 Ozaki M, Handa Y, Okabe M, et al. Problem in the diagnosis of tricuspid insufficiency by contrast echocardiography injected in the peripheral vein; on the false positive findings in normal subjects. Foumal of Cardiography 1980; 10: 173-86.

14 Kalmanson D, Veyrat C, Chiche P. Diagnostic par voie externe des cardiopathies droites et des shunts intra cardiaques gauche-droite à l'aide du flux-mètre directionnel à effect Doppler. Presse Med 1970; 78: 1053-6.

15 Kalmanson D, Derai C, Novikoff N. Le flux tricuspidien étudié chez l'animal et chez l'homme par cathétérisme vélocimétrique directionnel. Arch Mal Coeur 1971; 64: 854-73.

16 Kalmanson D, Veyrat C. Clinical aspects of venous return: a velocimetric approach to a new system dynamics concept. In: Baan J, Noordergraaf A, Raines J, eds. Cardiovascular system dynamics. Cambridge, Massachusetts: MIT Press, 1978: 297-305.

17 Kalmanson D, Veyrat C, Abitbol G, Bouchareine F, Cholot N. Vélocimétrie Doppler pulsé associée à l'échocardiographie. Exploration non traumatique des cardiopathies valvulaires. Nouv Presse Med 1977; 6: 2849-52.

18 Kalmanson D, Veyrat C. Echo-Doppler velocimetry in cardiology. In: Hwang NHC, Gross DR, Patel DJ, eds.
Quantitative cardiovascular studies, clinical and research applications of engineering principles. Baltimore: University Park Press, 1979: 689-713.

19 Kalmanson D, Veyrat C, Berkman M, Malergue MC. Enregistrement du shunt des communications interauriculaires et interventriculaires et des insuffisances tricuspidiennes par vélocimétrie Doppler pulsée. Nouv Presse Med 1979; 8: 1350.

20 Fantini F, Magherini A. Detection of tricuspid regurgitation with pulsed Doppler echocardiography. In: Lancee CT, ed. Echocardiology. The Hague: Martinus Nijhoff, 1979: 233-5.

21 Veyrat C, Kalomanson D. Clinical applications of pulsed Doppler velocimetry in cardiology. In: Rybak B, ed. Advanced technobiology. German Town, Maryland: Sijthoff \& Noordhoff, 1979: 317-39.

22 Veyrat C, Abitbol G, Berkman M, Malergue MC, Kalmanson D. Diagnostic et évaluation par écho-Doppler pulsé des insuffisances tricuspidiennes et des communications interventriculaires et interauriculaires. Arch Mal Coeur 1980; 73: 1037-52.

23 Waggoner AD, Quinones MA, Verani MS, Miller RR. Pulsed Doppler echocardiographic detection of tricuspid insufficiency: diagnostic sensitivity and correlation with right ventricular hemodynamics (abstract). Circulation 1978; 57 and 58, suppl. 11: 41.

24 Waggoner AD, Quinones MA, Young JB et al. Pulsed Doppler echocardiographic detection of right-sided valve regurgitation. Experimental results and clinical significance. Am f Cardiol 1981; 47: 279-86.

25 Kalmanson D, Veyrat C, Abitbol G. L'exploration valvulaire non-invasive par vélocimétrie scanner-Doppler pulsé. Coeur Med Interne 1980; 19: 237-46.

26 Baker DW, Rubenstein SA, Lorch GS. Pulsed Doppler echocardiography. Principles and applications. Am $\mathfrak{F}$ Med 1977; 63: 69-80.

27 Bazett HC. An analysis of the time-relations of electrocardiograms. Heart 1920; 7: 353-70.

28 Folts JD, Young WP, Ravnan ML, Rowe GG. Phasic tricuspid flow in chronic anesthetized dogs. $\mathcal{F} A p p l$ Physiol 1973; 34: 519-22.

29 Tsakiris AG, Mair DD, Seki S, Titus JL, Wood EH. Motion of the tricuspid valve annulus in anesthetized intact dogs. Circ Res 1975; 36: 43-8.

30 Tunstall Pedoe DS, MacPherson PC, Meldrum SJ. Absolute intracardiac blood velocities measured with continuous wave Doppler and a new real time spectral display. In: Lancee CT, ed. Echocardiology. The Hague: Martinus Nijhoff, 1979: 77-80.

31 MacPherson PC, Meldrum SJ, Tunstall Pedoe DS. Angioscan: a spectrum analyser for use with ultrasonic Doppler velocimeters. F Med Eng Technol 1981; 5: 84-5.

Requests for reprints to Dr Colette Veyrat, Service de Cardiologie, Fondation A de Rothschild, 25-29 rue Manin, 75940 Paris Cedex 19, France. 